There were no signs of infection and therefore a Müller type of cemented prosthesis was inserted. His postoperative progress was uneventful and he is now walking using one crutch.

Discussion. The metallic head of the removed prosthesis had fractured leaving two hemispherical parts. The fracture surfaces were flat planes and looked polished. It was evident that the two casted parts had been joined together by welding to form the complete sphere. This was also indicated by the symmetry and characteristic colouring of the inner surfaces of both parts, adjacent to the fracture. The colouring suggested that the material had been red-heated to achieve welding and that the fracture occurred between these welded surfaces, probably starting where there was a fault. The concentration of high stresses at this point presumably initiated the separation; time and continually repeated stress caused it to extend until eventually the head was in two pieces.
Other factors which may have been related to this implant failure are the patient's heavy weight; the fact that the arthroplasty was bilateral, and the contralateral prosthesis had been removed; and the previous loosening of the implant (Collis 1977; Galante 1980).

The authors thank Professor R. Grekoussis from the Department of Mechanical Engineering, Aristotelian University of Thessaloniki, for his comments on the fractured prosthesis.

No benefits in any form have been received or will be received from a commercial party related directly or indirectly to the subject of this article.

\section{REFERENCES}

Collis DK. Femoral stem failure in total hip replacement. $J$ Bone Joint Surg [ Am] 1977; 59-A:1033-41.

Galante JO. Causes of fractures of the femoral component in total hip replacement. J Bone Joint Surg [ Am] 1980; 62-A :670-3.

Galante JO, Rostoker W, Doyle JM. Failed femoral stems in total hip prostheses. J Bone Joint Surg [ Am] 1975; 57-A :230-6.

Miller EH, Shastri R, Shih CI. Fracture failure of a forged vitallium prosthesis. J Bone Joint Surg [Am] 1982; 64-A :1359-63.

\title{
BILATERAL CHONDROLYSIS WITH UNILATERAL SLIPPED CAPITAL FEMORAL EPIPHYSIS
}

\author{
R. K. MILLER, M. B. MENELAUS
}

Chondrolysis is a well recognised although uncommon complication of slipped capital femoral epiphysis (SCFE). We report a case of bilateral chondrolysis in the presence of unilateral SCFE. This combination has not, as far as we know, been previously reported.

Case report. A 16-year-old white male presented with a four-month history of right thigh pain and limp. He was at the 50th percentile for height and weight and there was no evidence of generalised disorder or hypogonadism. The right lower limb was $2 \mathrm{~cm}$ short and the hip had $25^{\circ}$ of fixed external rotation. The left hip and spine were normal. Radiographic examination revealed a chronic grade 3 SCFE on the right and bilateral protrusio acetabuli. There was a cyst, with no surrounding sclerosis, in the left femoral head.

The epiphysis was fixed without reduction. Five months later the patient presented with increasing right hip pain and stiffness. Plain radiographs demonstrated joint space narrowing, confirming a clinical diagnosis of chondrolysis (Fig. 1). Conservative treatment failed and

R. K. Miller, FRACS, Registrar

M. B. Menelaus, MD, FRCS, FRACS, Director

Department of Orthopaedic Surgery, Royal Children's Hospital, Flemington Road, Parkville, Victoria 3052, Australia.

Correspondence to Mr M. B. Menelaus.

(C) 1991 British Editorial Society of Bone and Joint Surgery 0301-620X/91/3R $17 \$ 2.00$

J Bone Joint Surg [ Br] 1991 ; 73-B:523-4.
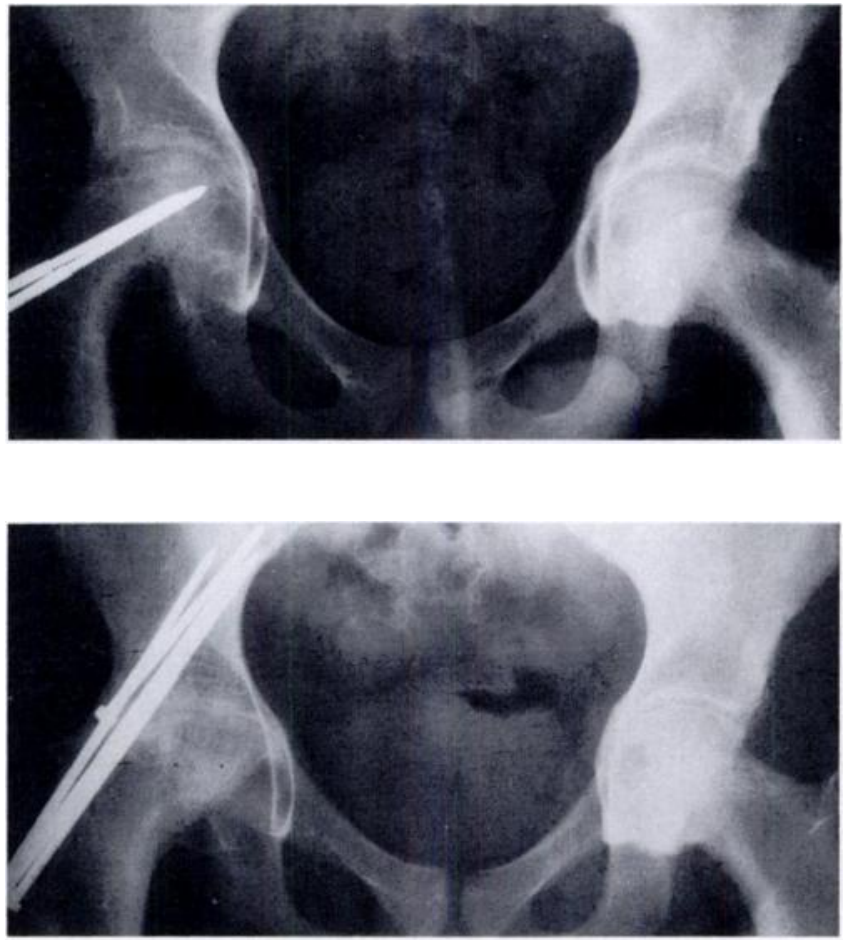

Fig. 2

he subsequently underwent right hip arthrodesis. No radiological features of total or segmental avascular necrosis had developed.

Fourteen months after his initial operation the patient presented again with left hip pain and stiffness of 
recent onset. Radiographs showed narrowing of the joint space on the left and a sound arthrodesis of the right hip (Fig. 2). The protrusio was unaltered as was the cyst in the left femoral head. There were no radiological changes in the sacro-iliac joints. Investigations including full blood count, ESR, rheumatoid factor, and antinuclear factor were normal and the HLA-B 27 was negative. There was no family history of collagen disorder or of familial protrusio acetabuli.

The chondrolysis of the left hip was treated by a period of non-weight-bearing and Naprosyn. A satisfactory clinical response followed and the patient is now active with only minimal discomfort.

Discussion. This patient is the first to provide a link between idiopathic chondrolysis and chondrolysis associated with SCFE. It has been assumed that these are the same condition with a shared aetiology and our case confirms this view. The causation of chondrolysis remains unknown. In our patient there was no evidence of underlying or coexisting collagen or other disease. There was a minor degree of protrusio of each acetabulum and a cyst in the left femoral head, but no evidence of familial protrusio.

Waldenström (1930) suggested that SCFE may result from inflammatory synovitis and several authors have subsequently investigated the possibility that SCFE and chondrolysis may share a common immunological basis. Synovitis is well documented in patients with SCFE; it is present early in the disease and usually resolves when the epiphysis has been internally fixed. Immune complexes and lymphocyte infiltrate have been demonstrated in the synovium of affected patients (Busch and Morrissy 1987). Altered immunoglobulin patterns have been observed in both the serum and synovial fluid of affected patients (Eisenstein and Rothschild 1976). These findings reflect the activity of the immune system in patients with SCFE, but it is not known whether the inflammatory process is primary or secondary. It is clear that the pathological changes described cannot be accounted for by the biomechanical (Chung, Batterman and Brighton 1976) or endocrine (Harris 1950) theories of SCFE.

No benefits in any form have been received or will be received from a commercial party related directly or indirectly to the subject of this article.

\section{REFERENCES}

Busch MT, Morrissy RT. Slipped capital femoral epiphysis. Orthop Clin North Am 1987; 18:637-47.

Chung SMK, Batterman SC, Brighton CT. Shear strength of the human femoral epiphyseal plate. J Bone Joint Surg [Am] 1976; 58-A: 94-103.

Eisenstein A, Rothschild S. Biochemical abnormalities in patients with slipped capital femoral epiphysis and chondrolysis. J Bone Joint Surg [ Am] 1976; 58-A :459-67.

Harris WR. The endocrine basis for slipping of the upper femoral epiphysis. J Bone Joint Surg [Br] 1950; 32-B:5-11.

Waldenström $\mathbf{H}$. On necrosis of the joint cartilage by epiphyseolysis capitis femoris. Acta Chir Scand 1930; 67:936-46.

\section{CORRECTION}

Wozasek GE, Moser K-D. Percutaneous screw fixation for fractures of the scaphoid.

J Bone Joint Surg [Br] 1991 ; 73-B:138-42.

The authors have informed us that the patients they reported were treated at the Trauma Clinic in Linz, Austria. The paper was prepared and forwarded to the Journal from the University School of Medicine, Vienna. 